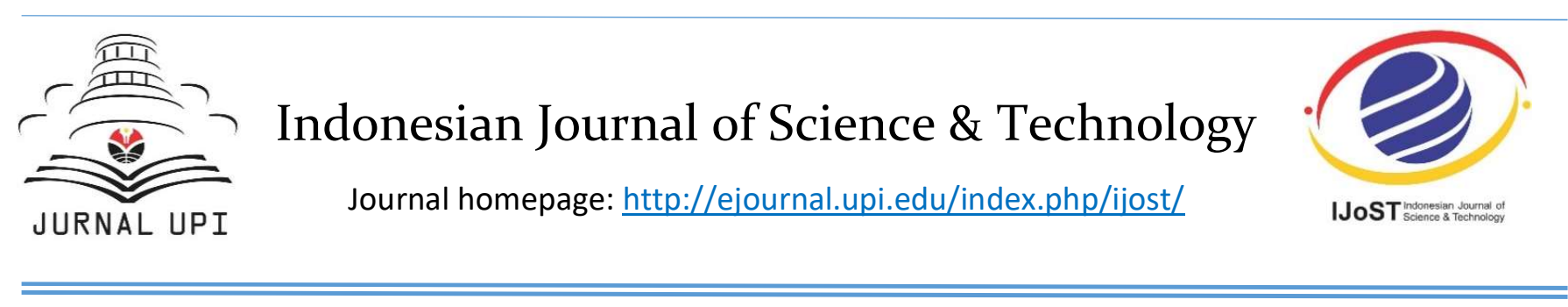

\title{
Students' Algebraic Proficiency from the Perspective of Symbol Sense
}

\author{
Al Jupri ${ }^{1 *}$, Ririn Sispiyati ${ }^{1}$ \\ ${ }^{1}$ Department of Mathematics Education, Faculty of Mathematics and Science Education, \\ Universitas Pendidikan Indonesia, Bandung, Indonesia \\ *Correspondence: E-mail: aljupri@upi.edu
}

ABSTRACT

Algebraic proficiency, including procedural fluency and conceptual understanding, is widely discussed worldwide. Algebraic proficiency refers largely to proficiency in symbolic representations which can be investigated through a framework of symbol sense. This research, therefore, aims to analyze students' algebraic proficiency in terms of symbol sense. We set up a pilot study, involving 22 Indonesian mathematics education students (18-19 year old), in the form of two weeks teaching that combine a conventional approach and the use of a camera calculator in the learning and teaching of quadratic and related equations. The results showed that more than half number of students lacks of symbol sense in the sense that they tend to use procedural strategies rather than symbol sense strategies in solving equations. From the perspective of symbol sense, we concluded that the students acquired more on procedural fluency than on conceptual understanding.

\begin{tabular}{l} 
A R T I C LE I N F O \\
\hline Article History: \\
Submitted/Received 09 Aug 2019 \\
First revised 02 Dec 2019 \\
Accepted 24 Jan 2020 \\
First available online 28 Jan 2020 \\
Publication date 01 Mar 2020 \\
\hline Keywords: \\
Algebra Education, \\
Algebraic Proficiency, \\
Symbol Sense, \\
Quadratic Equations, \\
Photomath.
\end{tabular}

(C) 2020 Tim Pengembang Jurnal UPI

\section{INTRODUCTION}

In international survey study, such as in Trends in International Mathematics and Science Study (TIMSS) in 2011, Indonesian students had low score in algebra, i.e., Indonesian students were in $38^{\text {th }}$ position out of 42 countries (Mullis et al., 2012). To explain this low score in algebra, a previous study has investigated student difficulties in initial algebra, in which the results revealed that Indonesian students lack of both algebraic procedural skills and conceptual understanding (Jupri et al., 2014). The procedural skills and conceptual understanding are two main aspects of 
algebraic proficiency (Van Stiphout et al., 2013), which are needed for further study and for future professional life (Katz, 2007).

The case of Indonesian student low performance in algebra might be caused by low performance of mathematics teachers, and of prospective mathematics teachers. As an initial step to investigate this cause, we carried out a small-scale pilot study in which mathematics education students as prospective mathematics teachers were taught using a more conventional approach working on solving quadratic and related equations enriched with the use of a camera calulator, in this case Photomath. In this paper, we presented the findings of the pilot study which concern student algebraic proficiency and analyze them using the notion of symbol sense.

\section{THEORETICAL FRAMEWORK}

\subsection{Algebraic Proficiency}

Proficiency in algebra can be interpreted as a matter of proficiency with symbolic representations (Brown \& Quinn, 2007). Van Stiphout et al. (2013) reported procedural fluency, and conceptual understanding are central in discussing algebraic proficiency, particularly for addressing algebraic expressions and equations.

Procedural fluency includes skill in carrying out procedures flexibly, accurately, efficiently, and appropriately; and conceptual understanding refers to comprehension of mathematical concepts, operations, and relations (Kilpatrick, 2001). According to Van Stiphout et al. (2013), procedural fluency and conceptual understanding have to go hand in hand in encouraging proficiency in algebra and in developing algebraic expertise in particular. Algebraic expertise ranges from basic skills such as procedural work with a local focus and algebraic manipulation to strategic work, which requires a global focus and algebraic reasoning and conceptual understanding (Bokhove \&
Drijvers, 2012). This strategic work with a global focus and emphasis on algebraic reasoning is part of symbol sense behavior (Bokhove \& Drijvers, 2010).

\subsection{Symbol Sense}

The idea of symbol sense, introduced by Arcavi (1994), is not yet defined precisely, but it includes an intuitive feel for when to use symbols and when to disregard them in the process of solving a problem. Symbol sense, which is an analogy of number sense, can be described as an ability to give meaning and to see important structures to symbols, algebraic expressions, and formulas (Arcavi, 2005). The acquisition of symbol sense is considered an important aspect for the success of learning algebra (Bokhove \& Drijvers, 2010; Van Stiphout et al., 2013). Furthermore, symbol sense is seen as an ability that shows proficiency in algebra (Van Stiphout et al., 2013), which indicates a relational rather than only an instrumental understanding (Skemp, 1976). Characteristics of symbol sense, summarized by Arcavi (2005) and are relevant to solving algebraic equations, include: (i) the ability to use symbols in recognizing relationship, in displaying generalization and proofs; (ii) the skill to read through and manipulate symbolic expressions; and (iii) the skill to check for the symbol meanings in the implementation of a procedure, the solution of a problem, or during the inspection of a result.

The notion of symbol sense has been used in previous studies, for instance, (i) for understanding student difficulties on the concept of parameter (Drijvers, 2000); (ii) forinvestigating student algebraic expertise in a digital environment (Bokhove \& Drijvers, 2010); (iii) for assessing algebraic proficiency (Van Stiphout et al., 2013); and (iv) in case of Indonesia, for understanding students' algebraic thinking in solving substitution problems (Jupri et al., 2016). In the present study, in which the use of technology is integrated in education similar to its 
integration to other subjects (see Rohmah \& Rachmawati, 2019), the lens of symbol sense is used for analyzing student algebraic proficiency.

\section{METHODS}

This pilot study was carried out in the following four steps.

First, we designed a teaching sequence and tasks on quadratic and related equations. These equations topics includeed: definition and characteristics of a quadratic equation, solution methods for solving quadratic equations, and related equations that include quadratic expressions. The related equations included cubic and rational equations. This teaching design was implemented for 22 first year mathematics education students (18-19 year-old) who attended the School Mathematics course. The tasks, for assessing students, were designed according to characteristics of symbol sense. Table 1 shows the relationship between main characteristics of symbol sense, task types, and test items for this study.

Second, we implemented the teaching design in a two-week of learning and teaching process, lasted for $4 \times 50$ minutes, using a blended approach. This teaching approach combines conventional teaching with a camera calculator-in this case Photomath. By the conventional teaching approach, we mean the approach of a direct teaching, in which the lecturer explains a topic, gives examples, and exercises; while the students pay attention to the lecturer, take notes, do the exercises, and present their work on the blackboard either individually or in groups of two. During the learning and teaching process, the lecturer taught both procedural strategies and more efficient strategies by applying symbol sense characteristics. By the Photomath, we mean a mobile application in the form of a camera calculator that utilizes a phone's camera to recognise mathematical equations and to display the step-by-step solution on screen (Webel, \& Otten, 2016). In the learning and teaching process, in which each student has a smartphone with the Photomath in it, the Photomath was used as a tool for instance, checking an equation solving process and providing an idea if a student encountered difficulty in the equation solving process.

Figure 1 shows an example of the use of Photomath to solve the quadratic equation $(3 x+4)^{2}+2019=2025$. Figure 1 part 1 shows an equation was captured by the Photomath camera with its solution; and Figure 1 parts 2-4 show the step-by-step solution provided by the Photomath. This step-by-step solution is considered to be a standard procedure focusing more on a procedural strategy rather than on the use of symbol sense strategy. In addition to procedural step-by-step solution, Photomath also provides a graphical representation of the solved equation.

Third, after the two-week lesson, we tested students' algebraic proficiency on solving equations with the tasks described in Table 1. The test was lasted for 30 minutes for the three tasks. During the test, students were not allowed to use Photomath or other electronic devices. From this test, we collected all written student work data including their scrap papers.

Fourth, and final, we analyzed the written student work data using the lens of symbol sense. The analysis included identification of strategies used by students for solving equations, and identification of student difficulties in solving the equations. We classified an equation solving strategy as symbol sense strategy if a student uses symbol sense characteristics, and as a procedural strategy if not. These identifications guided us to evaluate whether the students have acquired both procedural fluency and conceptual understanding sufficiently. 
89| Indonesian Journal of Science \& Technology, Volume 5 Issue 1, January 2020 Hal 86-94

Table 1. Relationship between symbol sense characteristics and tasks

\begin{tabular}{clc}
\hline $\begin{array}{c}\text { Type of } \\
\text { tasks }\end{array}$ & \multicolumn{1}{c}{ Characteristics of symbol sense } & Tasks \\
\hline 1 & $\begin{array}{l}\text { Check symbol meanings before or during } \\
\text { the use of a procedure, the solution of a } \\
\text { problem, and during the inspection of a } \\
\text { result. }\end{array}$ & $(3 x+4)^{2}+2019=2025$ \\
2 & $\begin{array}{l}\text { Recognize symbolic relationship, display and } \\
\text { do symbolic generalization and proofs. } \\
\text { Read through and manipulate symbolic ex- } \\
\text { pressions. }\end{array}$ & $\left(4 x^{2}+5 x-4\right)(2 x+1)=(2 x+1)(x-1)$ \\
&
\end{tabular}

(a)

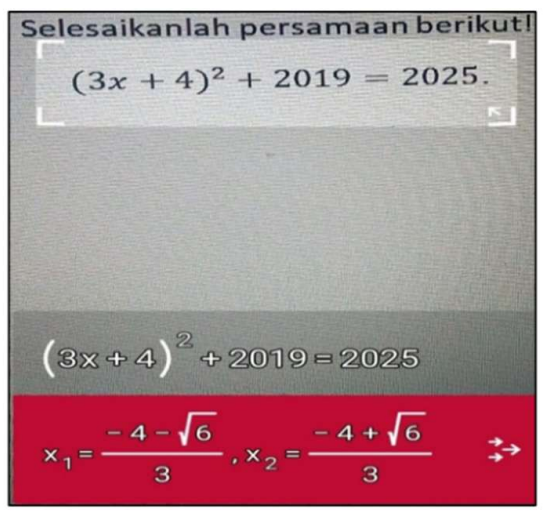

(c)

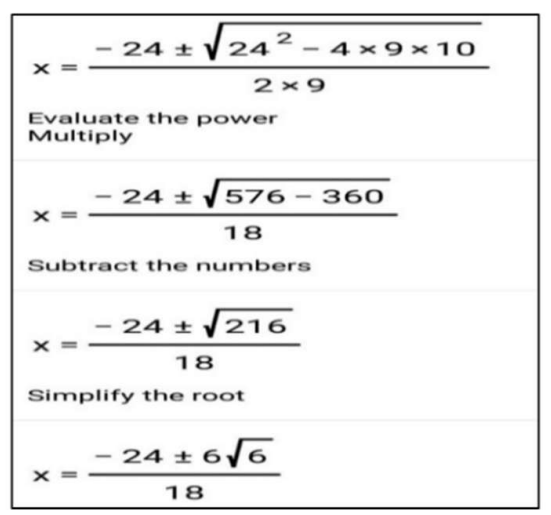

(b)

$(3 x+4)^{2}+2019=2025$
Expand the expression
$9 x^{2}+24 x+16+2019=2025$
Add the numbers
$9 x^{2}+24 x+2035=2025$
Move constant to the left
$9 x^{2}+24 x+2035-2025=0$
Subtract the numbers
$9 x^{2}+24 x+10=0$
Solve the quadratic equation

(d)

$x=\frac{-24+6 \sqrt{6}}{18}$
$x=\frac{-24-6 \sqrt{6}}{18}$
Simplify the expressions
$x=\frac{-4+\sqrt{6}}{3}$
$x=\frac{-4-\sqrt{6}}{3}$
The final solutions are
$x_{1}=\frac{-4-\sqrt{6}}{3}, x_{2}=\frac{-4+\sqrt{6}}{3}$

Figure 1. A scenario for solving an equation using Photomath. Figures (a), (b), (c), and (d) are the steps used for solving problems, corresponding to steps (1), (2), (3), and (4), respectively. 


\section{RESULTS AND DISCUSSION}

Table 2 presents findings of student written work data on solving equations. We consider these findings as a qualitative effect of the blended teaching approach enriched with the use of Photomath toward students' algebraic proficiency. In general, by considering the number of correct answers, task type 3 is the most difficult, and task type 2 is more difficult than task type 1. Also, even if we observed that both procedural and symbol sense strategies emerge, the emergence of procedural strategies is more frequent than the symbol sense strategies. This means the acquisition of procedural skills is more dominant than conceptual understanding. Below, we addressed further about these findings.

\subsection{Results and discussion for task type 1}

From the data shown in Table 1, the task of type 1 is solved correctly by 12 out of 22 students (54.5\%). From the perspective of symbol sense, the more frequent emergence of the procedural strategies compared than the symbol sense strategies for solving this task (90.9\%). It shows that the students seem not to check the meaning of the equation before solving it. Instead, students were directly encouraged to use a standard procedure that they already know without first understanding the meaning of the equation.

A typical procedural strategy for solving equation $(3 x+4)^{2}+2019=2025$ used by the students is quite similar with the procedure produced by the Photomath shown in Figure 1. After expanding the term $(3 x+4)^{2}$ and doing some calculations, students obtained $9 x^{2}+24 x+10=0 . \quad$ Correct solutions were produced by students who used a quadratic formula for solving quadratic equation; whereas incorrect solutions oc- curred when students tried to use a factorization method (which is impossible to find in this case), and make mistakes in doing calculations. The finding of student difficulty in determining whether a quadratic equation can be factored into rational factors or not indicated that the students do not perfectly master the factorization method for solving quadratic equations. This means that procedural fluency of the students is not perfectly achieved.

A typical symbol sense strategy used by students for solving the equation is as follows. The equation $(3 x+4)^{2}+2019=2025$ is seen as a calculation of $\ldots+2019=2025$. This leads to $(3 x+4)^{2}=6$, which therefore $3 x+4=\sqrt{6}$ or $3 x+4=-\sqrt{6}$. Next, by solving these two linear equations, the students conclude $x=(\sqrt{6}-4) / 3$ or $x=$ $(-\sqrt{6}-4) / 3$ as the solutions of the equation. In the light of symbol sense, the use of this strategy shows that the students checked the meaning of the equation and chose a more efficient procedure for the solution process. This means that the students use more on conceptual understanding than only procedural fluency in the solution process.

The more frequent use of procedural than symbol sense strategies indicates that the use of Photomath had influenced student thinking in the process of equation solving. This finding is in line with the findings of, for instance, Drijvers et al. (2013) and Jupri, et al. (2016), in which students' strategies are similar to strategies provided by digital technologies.

\subsection{Results and discussion for task type 2}

As shown in Table 2, the task of type 2 can be solved correctly by less than half of total number of students (40.9\%). Even if the use of symbol sense strategies was quite frequent $(36,4 \%)$, still the use of procedural 
strategies was dominant. Typical procedural and symbol sense strategies for solving the equation

$\left(4 x^{2}+5 x-4\right)(2 x+1)=(2 x+1)(x-1) \quad$ used by the students are shown in Figure 2. Figure $\mathbf{2}$ in the left screen shows a procedural strategy, and that in the right screen shows a symbol sense strategy.

We observed that six students encountered difficulties in solving the equation using the procedural strategies when they obtained $8 x^{3}+12 x^{2}-2 x-3=0$ (see line 4 Figure 2 of the left part). The students were not able to factorize this cubic equation into rational factors. Two students made mistakes on expanding algebraic expressions. These difficulties indicated that the students did not master the standard procedural strategy in solving polynomial equations in general and in solving quadratic and related equations in particular.

A typical symbol sense strategy that was used imperfectly by five students occurred when they cancelled the term $(2 x+1)$ from both sides of the equation $\left(4 x^{2}+5 x-4\right)(2 x+$ 1) $=(2 x+1)(x-1)$ to get $4 x^{2}+5 x-4=x-1$. Next, they solved this quadratic equation to obtain $x=-3 / 2$ and $x=1 / 2$ as the solutions. These solutions are therefore incomplete.

The frequent use of symbol sense strategies might be caused by both examples given by the lecturer and the use of Photomath during the learning and teaching process. For this case, Photomath provides also an efficient symbol sense strategy.

The use of symbol sense strategies for solving the task type 2 indicated that the students recognized a symbolic relationship in terms of observing the same terms on both sides of the equation. Recognizing the same terms can be seen as recognizing an algebraic structure, which in the literature refers to structure sense ability (Novotna \& Hoch, 2008; Hoch \& Dreyfus, 2005), which is an extension of symbol sense ability.

\subsection{Results and discussion for task type 3}

The task type 3 is the most difficult one: only seven out of 22 students (31.8\%) solved the equation correctly (see Table 2). This can be understood because the task is a rational equation that involves quadratic expressions. Again, in terms of strategies, procedural strategies were used more frequent than symbol sense strategies.

A typical procedural strategy used by students for solving the equation $(1-x-$ $\left.2 x^{2}\right) /\left(2 x^{2}+5 x+3\right)=2 x-1$ is as follows. $\left(1-x-2 x^{2}\right) /\left(2 x^{2}+5 x+3\right)-(2 x-1)=0$. $\Leftrightarrow\left(-4 x^{3}-10 x^{2}-2 x+4\right) /\left(2 x^{2}+5 x+3\right)=0$. $\Leftrightarrow-4 x^{3}-10 x^{2}-2 x+4=0$. $\Leftrightarrow(-4 x-4)(x+2)(x-1 / 2)=0$. $\Leftrightarrow x=-2, x=1 / 2$, or $x=-1$.

Since $x=-1$ implies the denominator of the equation equals zero, the solutions therefore include only $x=-2$ or $x=1 / 2$.

A common difficulty encountered by ten students who used the procedural strategies is factorizing the expression of $-4 x^{3}-10 x^{2}-$ $2 x+4$ into $(-4 x-4)(x+2)(x-1 / 2)$. This means the students lacked of procedural fluency in factorizing polynomials.

A typical symbol sense strategy used by students for solving the equation $(1-x-$ $\left.2 x^{2}\right) /\left(2 x^{2}+5 x+3\right)=2 x-1$ is as follows. $(1+x)(1-2 x) /(1+x)(3+2 x)+(1-2 x)=0$.

For $x \neq-1$, we have

$(1-2 x)(1 /(3+2 x)+1)=0$.

$\Leftrightarrow(1-2 x)(4+2 x) /(3+2 x)=0$.

$\Leftrightarrow(1-2 x)(4+2 x)=0$.

$\Leftrightarrow x=-2$ or $x=1 / 2$.

The use of the symbol sense strategy makes use symbol sense characteristics of reading through before manipulating symbolic expressions. This indicates that the acquisition of students more on conceptual understanding than on procedural fluency. In line with the results of Van Stiphout et al. (2013) and Bokhove and Drijvers (2010), a common encountered difficulty in applying this symbol sense strategy is the ability to read through the quadratic expressions whether they can be factorized or not. 
Table 2. Results from data analysis of the written test $(\mathrm{N}=22)$

\begin{tabular}{cccrc}
\hline $\begin{array}{c}\text { Task } \\
\text { type }\end{array}$ & \multicolumn{1}{c}{ Tasks } & $\begin{array}{l}\text { \#Correct } \\
\text { solution (\%) }\end{array}$ & \multicolumn{2}{c}{ Solution strategies } \\
\cline { 4 - 5 } & & $12(54.5)$ & $20(90.9)$ & $2(9.1)$ \\
strocedural & $\begin{array}{c}\text { \#Symbol sense } \\
\text { strategy (\%) }\end{array}$ \\
\hline 1 & $(3 x+4)^{2}+2019=2025$ & $9(40.9)$ & $14(63.6)$ & $8(36.4)$ \\
2 & $\left(4 x^{2}+5 x-4\right)(2 x+1)=(2 x+1)(x-1)$ & $7(31.8)$ & $17(77.3)$ & $5(22.7)$ \\
3 & $\frac{1-x-2 x^{2}}{2 x^{2}+5 x+3}=2 x-1$ & & & \\
\hline
\end{tabular}
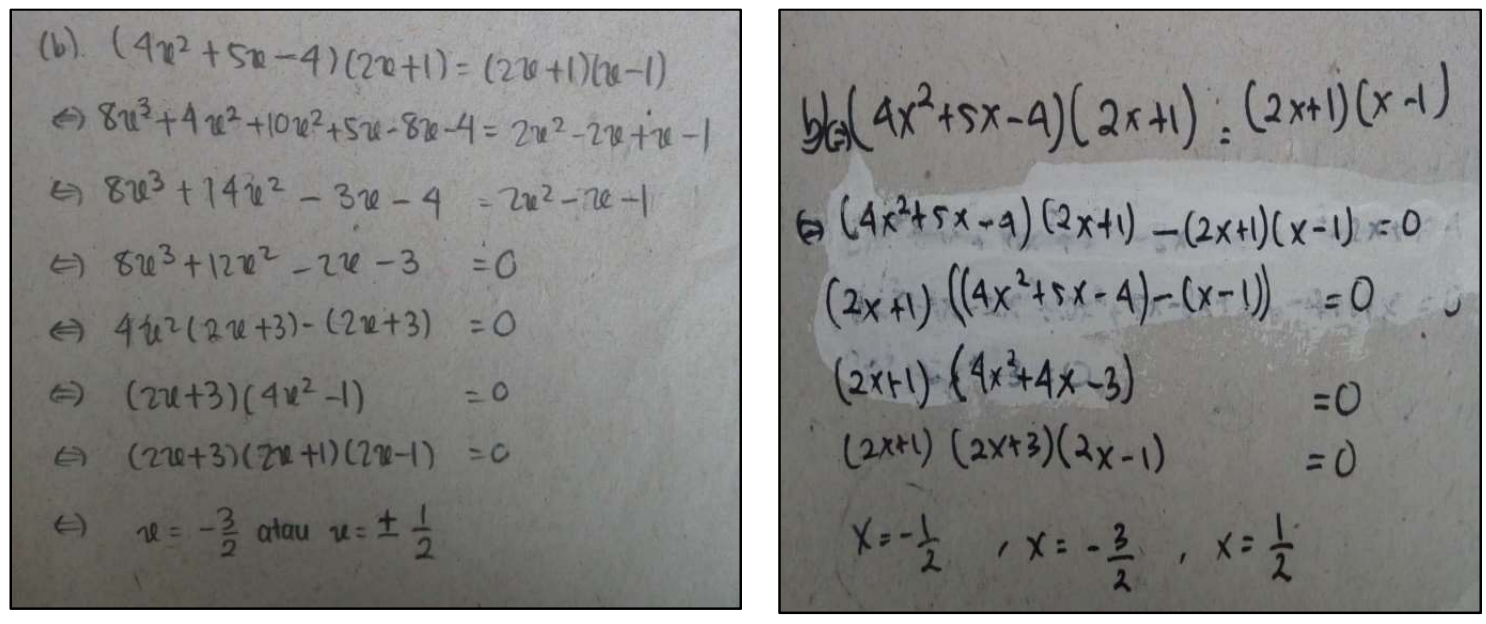

Figure 2. Student written work on task type 2

\section{CONCLUSION}

From the results described in the previous section we draw the following conclusions. First, in general, the more frequent use of procedural than symbol sense strategies for solving equations shows that students tend to acquire more on procedural fluency than on conceptual understanding. From the perspective of symbol sense this means that students lack of symbol sense ability.

Second, main difficulty encountered by students in applying either symbol sense or procedural strategies is factorizing algebraic expressions. Students lack of ability in recognizing whether a quadratic form can be factorized or not, and in determining whether a cubic form can be factorized into rational factors or not.
Third, the fact that students use more on procedural strategies might be caused by the use of Photomath that provides more on standard procedural strategies. Another cause might be caused by lacked examples from the lecturer during the learning process.

\section{ACKNOWLEDGEMENTS}

This research was funded by DRPM DIKTI through Penelitian Dasar research scheme year 2019, No 171A/UN40.D/PP/2019. We thank students who participated in this study.

\section{AUTHORS' NOTE}

The author(s) declare(s) that there is no conflict of interest regarding the publication of this article. Authors confirmed that the data and the paper are free of plagiarism. 


\section{REFERENCES}

Arcavi, A. (1994). Symbol sense: Informal sense-making in formal mathematics. For the Learning of Mathematics, 14(3), 24-35.

Arcavi, A. (2005). Developing and using symbol sense in mathematics. For the Learning of Mathematics, 14(3), 42-47.

Bokhove, C., \& Drijvers, P. (2010). Digital activities for capturing symbol sense. For the Learning of Mathematics, 30(3), 43-49.

Bokhove, C., \& Drijvers, P. (2012). Effects of feedback in an online algebra intervention. Technology, Knowledge and Learning, 17(1-2), 43-59.

Brown, G., \& Quinn, R. J. (2007). Investigating the relationship between fraction proficiency and success in algebra. Australian Mathematics Teacher, 63(4), 8-15.

Drijvers, P. (2000). Students encountering obstacles using a CAS. International Journal of Computers for Mathematical Learning, 5(3), 189-209.

Drijvers, P., Godino, J. D., Font, V., \& Trouche, L. (2013). One episode, two lenses: a reflective analysis of student learning with computer algebra from instrumental and onto-semiotic perspectives. Educational Studies in Mathematics, 82(1), 23-49.

Hoch, M., \& Dreyfus, T. (2005). Students' Difficulties with applying a familiar formula in an unfamiliar context. International Group for the Psychology of Mathematics Education, 3, 145-152.

Jupri, A., Drijvers, P., \& Van den Heuvel-Panhuizen, M. (2014). Difficulties in initial algebra learning in Indonesia. Mathematics Education Research Journal, 26(4), 683-710.

Jupri, A., Drijvers, P., \& Van den Heuvel-Panhuizen, M. (2016). An instrumentation theory view on students' use of an applet for algebraic substitution. International Journal for Technology in Mathematics Education, 23(2), 63-80.

Katz, V. J. (2007). Stages in the history of algebra with implications for teaching. Educational studies in mathematics, 66(2), 185-201.

Kilpatrick, J. (2001). Understanding mathematical literacy: The contribution of research. Educational studies in mathematics, 47(1), 101-116.

Mullis, I. V. S., Martin, M. O., Foy, P., \& Arora, A. (2012). TIMSS 2011 international results in mathematics. Boston: TIMSS \& PIRLS International Study Center.

Novotná, J., \& Hoch, M. (2008). How structure sense for algebraic expressions or equations is related to structure sense for abstract algebra. Mathematics Education Research Journal, 20(2), 93-104.

Rohmah, A. A., \& Rachmawati, R. (2019). Utilization and quality of information system for administration services based on ICT in Patehan, Kraton, Yogyakarta. Indonesian Journal of Science and Technology, 4(1), 55-63. 
Skemp, R. R. (1976). Relational understanding and instrumental understanding. Mathematics Teaching, 77(1), 20-26.

Van Stiphout, I., Drijvers, P., \& Gravemeijer, K. (2013). The development of students' algebraic proficiency. International Electronic Journal of Mathematics Education, 8(2-3).

Webel, C., \& Otten, S. (2016). Teaching in a world with photomath. Mathematics Teacher, 109(5), 368-373. 